\section{HYPERCALCAEMIA AND DIFFUSE OSTEOLYT- IC LESIONS IN THE ACUTE PHASE OF MYELOID SPLENOMEGALY}

\section{To the Editor}

Lytic bone lesions and hypercalcaemia are frequent in lymphoproliferative disorders, especially with multiple myeloma and lymphoma (1). However, lytic bone lesions and/or hypercalcaemia are exceptional in myeloproliferative disorders (2). We present a patient in whom the blast crisis of myeloid splenomegaly was associated with hypercalcaemia and destructive bone lesions.

A 54-year-old woman with an 13-year history of myeloid splenomegaly, treated with hydroxyurea, was admitted to our department because of weakness, anorexia, weight loss and bone pain. On physical examination, there was hepatomegaly and multiple nodular tumoral skin lesions, but no lymphadenopathy or splenomegaly (splenectomy 3 months prior to admission). Blood cell counts showed haemoglobin $10 \mathrm{~g} / \mathrm{dl}$, white count cells $27.3 \times 10^{9} / 1$ with $70 \%$ blast cells and platelets $40 \times 10^{9} /$ l. Serum creatinine was $198 \mathrm{umol} / \mathrm{l}$, phosphor was high and parathormone normal. Serum calcium was $3.3 \mathrm{mmol} / \mathrm{l}$ and serum alkaline phosphatase was $179 \mathrm{UI} / \mathrm{l}$. No monoclonal gammapathy was demonstrated in serum or urine, but skeletal $\mathrm{X}$-ray films showed osteolytic lesions, mimicking multiple myeloma on skull (Fig. 1) and proximal long bones. Bone marrow aspirate and biopsy and skin tumour biopsy were performed showing diffuse marrow infiltration by FAB megacaryoblastic blast cells (M7) (cytologic aspect, histochemical stains and immunologic typing). The patient died one month after admission because of refractory leukaemia and unresponsive chest infection (despite rapid decrease in calcium level by conventional treatment).

This case report of myeloid splenomegaly is remarkable for its clinical course with blast crisis of FAB M7 type associated with hypercalcaemia and destructive bone lesions mimicking multiple myeloma. The pathogenetic mechanism of hypercalcaemia and lytic bone lesions is unknown in acute phase of myeloproliferative disorders. There is no evidence that pros

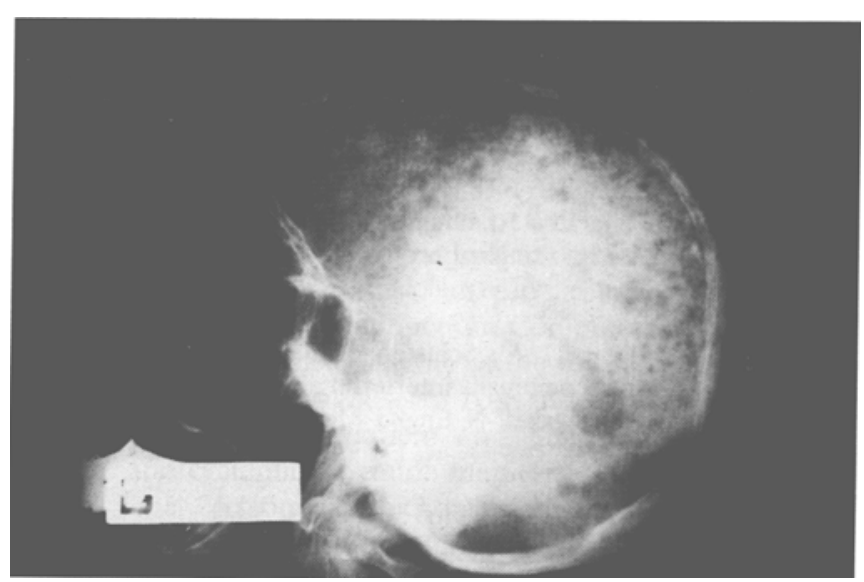

Fig. I: Multiple Osteolytic lesions in the skull. taglandins, osteoclast activating factor (interleukin 1, tumour necrosis factor), vitamin D or parathormone play an essential role (2). In our case report, it is very attractive to suppose that the M7 blast cells were responsible for the hypercalcaemia with secretion of bone resorptive factors (in particular the platelet derived growth factor which was found to possess potent bone-resorbing properties in vitro) (3).

B. TAILLAN,

E. FERRARI,

G. GARNIER,

H. VINTI,

A. PESCE,

\section{P. DUJARDIN}

Department of Internal Medicine, Cimiez Hospital, 06003 Nice, France.

\section{REFERENCES}

1. Rossi, J.F., Bataille, R., Chappard, D., Alexandre, C., Janbon, C. $B$ cell malignancies presenting with unusual bone involvement and mimicking multiple myeloma. Am J Med 1987, 83, 10-16.

2. Tricot, G., Boogaerts, M.A., Broeckaert-Van-Orshoven, A., Criel, A., Van Hoof, A., Vandenberghe, H. Hypercalcaemia and diffuse osteolytic lesions in the acute phase of chronic myelogenous leukemia. Cancer 1983, 52, 841-845.

3. Ralston, S.H. The pathogenesis of humoral hypercalcemia of malignancy. Lancet 1987, 2, 1443-1446.

Received-accepted: 7 April 1992

Correspondence to: Dr. B. TAILLAN,

Service de Médecine Interne I, Hôpital de Cimiez, BP 179, 06003 Nice Cedex 1, France.

\section{WHEN SHOULD ORTHOPAEDIC TREATMENT BE PRESCRIBED TO AVOID THE FLATTENING OF THE RHEUMATOID FOOT?}

\section{To the Editor}

In an X-ray study of 308 weight-bearing rheumatoid feet, the metatarsus primus adductus (MPA) appeared correlated with midfoot flattening (the internal arch angle was $\geqslant 130^{\circ}$ ) and with tarsitis (joint narrowing) (1). Over a certain period of time, we looked for a succession of radiological symptoms on the same sample of patients. If one particular symptom did actually arise before the flattening, this would be a motive for prescribing preventive orthopaedic treatment.

Keeping this in mind, we compared the duration of the disease for the patients who had a particular symptom; we did not collate the durations from the time that these symptoms appeared. We calculated the 95 th per cent confidence interval (CI) for the population which had a given symptom, with a 5 per cent risk; this means that for this particular symptom, the mean duration has a 95 per cent probability of being situated in this interval. If for two groups of feet affected by different symptoms the intervals are not connected, there is a significant difference between the average duration of the disease for the determinate risk $(5 \%)$. This method al- 